\title{
Initial Management of Burns in a Non-Specialized Burn Center
}

\author{
Edgar Vargas-Flores* \\ Department of General Surgery, Hospital General Regional 5, Mexico
}

Submission: July 10, 2017; Published: August 10, 2017

*Corresponding author: Edgar Vargas-Flores, Department of General Surgery, Hospital General Regional 5, Mariano Escobedo, Centro, 84000

Nogales, Sonora, Mexico, Tel: 525554995292; Email: eddgar868@gmail.com

\begin{abstract}
In low and middle income countries, burns are a major global public health problem. The burden of injury primarily affects low socioeconomic population. Basic measures applied to these patients may increase better outcomes even in health care centers that lack specialized resources. The initial assessment of a burn patient is no different of any patient exposed to trauma. Basic concepts should be applied and followed on this type of patients. The so called ABCDE is a short and easy to apply mnemonic in all of them. Pre-Burn center care is of paramount importance, and simple measures such as wound irrigation with cold water may be of great benefit for patients that are in need for a long distance transfer. This and an early fluid resuscitation greatly enhance the process of initial care in any burn patient. In the setting of a patient being treated in a rural or primary health care center, a proper initial evaluation and treatment as well as an early transfer to a specialized burn center is of paramount importance.
\end{abstract}

Keywords: Burns; Burn management; Resuscitation; BSA; Parkland formula

Abbreviations: GCS: Glasgow Coma Scale; BSA: Body Surface Area; TBSA: Total Body Surface Area; IV: Intravenous

\section{Introduction}

In low and middle income countries, burns are a major global public health problem [1]. The burden of injury primarily affects low socioeconomic population [2]. Children are mainly affected by this problem (usually less than 5 years old) $[3,4]$. Basic measures applied to these patients may increase better outcomes even in health care centers that lack specialized equipment, plastic surgeons or facilities to take care of burn patients. This review is aimed to highlight the most important aspects of the management of patients with second and thirddegree burns in a rural or primary health care center prior to its transfer to a proper specialized burn facility.

Patients suffering burn injuries are prone to develop a wide arrange of complications depending on the affected total body surface area affected. Patients with more than $20 \%$ of total body surface area may be prone to develop severe complications such as renal failure, infections and death. Not to mention the irreversible cosmetic complications.

Most burn resuscitation formulas estimate fluid requirements using the burn size as a percentage of TBSA (\%TBSA). The "rule of nines" is a quick and effective method of estimating burn size. In adults, the anterior and posterior trunk each account for $18 \%$, each lower extremity is $18 \%$, each upper extremity is $9 \%$, and the head is $9 \%$. Palms and genitalia account for $1 \%$ [5]. In children under 3 years old, the head accounts for a larger surface area. Only second and third-degree burns should be included when calculating the \%TBSA.

\section{Discussion}

\section{Initial management}

The initial assessment of a burn patient is no different of any patient exposed to trauma. Basic concepts should be applied and followed on this type of patients. The so called ABCDE is a short and easy to apply mnemonic in all of them.

A is for airway: A patent airway with cervical protection is the mainstay of the initial assessment. Signs of airway injury should be always suspected in patients exposed to burns in a closed environment. If intubation is required there should be no delay for it since airway edema may develop, making intubation difficult or impossible.

B is for breathing: Difficulties on breathing should alert the physician for circumferential burns in chest or abdomen as well 
as associated injuries such as thoracic trauma that may require additional invasive procedures.

C is for circulation: Insertion of one or two large bore peripheral IV catheters for fluid resuscitation is the mainstay in this part of the evaluation. Burn patients do not usually bleed. So if bleeding is found, an associated cause should be identified. Adequate monitoring of the circulatory status is mandatory.

D is for neurological deficit: Basic neurological evaluation with the GCS is a very easy and practical way to rapidly asses for any neurological deficit and even the need to intubate a burn patient when GCS is less than 8.

E is for exposure: Burn patients should have all their clothes and accessories such as bracelets or necklaces removed when arriving at the medical center, especially on a history of a chemical burn (since delay of this basic maneuver may worsen injuries). Anterior and posterior evaluation of the whole body should be assessed for injuries. After the evaluation, dry and clean sheets or towels should cover the patient to avoid hypothermia.

Patients with a burned body surface area of $20 \%$ are prone to develop gastric distention, nausea or vomiting so they must have a nasogastric tube placed as well as a Foley catheter for fluid balance [6].

\section{Fluid resuscitation}

Pre-Burn center care is of paramount importance. An early fluid resuscitation greatly enhance the process of initial care in any burn patient [7]. Those with burns of less than $10 \%$ of total body surface area may receive an oral resuscitation (unless the digestive tract or airway are affected by concomitant trauma). Burns greater than $10 \%$ total body surface area requires at least one peripheral intravenous line (or intraoseous line in children) for fluid resuscitation. Patients with a $30 \%$ affected body surface area may need two large bore peripheral IV catheters. 6 The parkland formula (Table 1) is a practical way to determine the amount of fluid needed for an adequate resuscitation $[6,8]$. Half of the total volume obtained by the Parkland formula is administered on the first 8 hours after the initial insult and the remaining is given on the next 16 hours.

Table 1: Parkland formula (ABLS 2014) ${ }^{27}$.

\begin{tabular}{|c|}
\hline Thermal and chemical burns (Adults) \\
\hline $2 \mathrm{ml} \times$ \%Burned BSA x Weight \\
\hline Pediatric patients (14-yo and Body weight of less than 40kg) \\
\hline $\begin{array}{c}\text { 3ml x \%Burned BSA } \mathrm{x} \text { Weight } \\
\text { High voltage electric injuries (evidence of deep tissue injury or } \\
\text { hemoglobinuria) }\end{array}$ \\
\hline $4 \mathrm{ml}$ x \%Burned BSA x Weight \\
\hline
\end{tabular}

\section{Pain control}

NSAIDs may play an important role in those patients that have a low risk of renal failure (non- diabetic, elderly or both, among others). Opioids may be safely indicated in patients with severe pain [9]. Subcutaneous and intramuscular administration should be avoided [6].

\section{Wound management}

From partial thickness to full thickness burns, simple coverage is necessary. Clean and dry sheets or towels may function as an effective coverage of wounds in burned patients since they provide a dry and warm environment avoiding heat loss. Some evidence suggests that an early and aggressive approach towards full thickness burns may be of great benefit (short and long term) in patients whom are treated in a burn center but not to those treated in a rural or primary health care center $[10,11]$.

Irrigation with cold water is considered an adequate first-aid treatment for burn injuries [12]. Superficial burns do not require antibiotics or special occlusive dressings. Nevertheless, deeper burns require topical antimicrobials or an absorptive occlusive dressing. Silver-based dressings or ointment such as sulfadiazine should be used if available [13]. Tetanus immunization is advised for any patient suffering a burn injury [6].

\section{Referral to a burn center}

Guidelines for referral to a burn center are depicted in Table 2.

Table 2: Guidelines for referral to a burn center.

\begin{tabular}{|c|}
\hline Partial-thickness burns greater than 10\% TBSA \\
\hline $\begin{array}{c}\text { Burns involving the face, hands, feet, genitalia, perineum, or major } \\
\text { joints }\end{array}$ \\
\hline Third-degree burns in any age group \\
\hline Electrical burns \\
\hline Chemical burns \\
\hline Inhalation injury \\
\hline Burn in a patient with complicated pre-existing medical problem \\
\hline Burned children in hospitals without qualified pediatrician \\
\hline $\begin{array}{c}\text { Burn injury in patients who will require special social, emotional, or } \\
\text { rehabilitative intervention }\end{array}$ \\
\hline
\end{tabular}

\section{Conclusion}

Each burn patient requires individualized care. Therefore, in the setting of a patient being treated in a rural or primary health care center a proper initial evaluation and treatment as well as an early transfer to a specialized burn center is of paramount importance.

\section{References}

1. Forjuoh SN (2006) Burns in low-and middle-income countries: a review of available literature on descriptive epidemiology, risk factors, treatment, and prevention. Burns 32(5): 529-537.

2. WHO (2008) Global burden of disease 2004 summary tables. Geneva (Switzerland): World Health Organization. 
3. Ahuja RB, Bhattacharya S (2002) An analysis of 11,196 burn admissions and evaluation of conservative management techniques. Burns 28(6): 555-561.

4. Atiyeh B, Masellis A, Conte C (2009) Optimizing burn treatment in developing low- and middle-income countries with limited health care resources (part 1). Ann Burns Fire Disasters 22(3): 121-125.

5. Freiburg C, Igneri P, Sartorelli K, Rogers F (2007) Effects of differences in percent total body surface area estimation on fluid resuscitation of transferred burn patients. J Burn Care Res 28(1): 42-48.

6. (2014) Advanced Burn Life Support (ABLS) Provider manual. American Burn Association.

7. Ahuja RB, Bhattacharya S (2004) Burns in the developing world and burn disasters. BMJ 329(7463): 447-449.

8. Singer AJ, Dagum AB (2008) Current management of acute cutaneous wounds. N Engl J Med 359(10): 1037-1046.
9. Stoddard FJ, Sheridan RL, Saxe GN, King BS, King BH, et al. (2002) Treatment of pain in acutely burned children. J Burn Care Rehabil 23(2): 135-156.

10. Munster AM, Smith-Meek M, Sharkey P (1994) The effect of early surgical intervention on mortality and cost effectiveness in burn care (1978-1991). Burns 20: 61-64.

11. Gallaher JR, Mjuweni S, Shah M, Cairns BA, Charles AG (2015) Timing of early excision and grafting following burn in sub-Saharan Africa. Burns 41(6): 1353-1359.

12. Skinner A, Peat B (2002)Burns treatment for children and adults: a study of initial burns first aid and hospital care. N Z Med J 115(1163): U199.

13. Sinha R (1990) Amniotic membrane in the treatment of burn injury. Indian J Surg 52: 11-17.

\section{Your next submission with Juniper Publishers will reach you the below assets}

- Quality Editorial service

- Swift Peer Review

- Reprints availability

- E-prints Service

- Manuscript Podcast for convenient understanding

- Global attainment for your research

- Manuscript accessibility in different formats

( Pdf, E-pub, Full Text, Audio)

- Unceasing customer service

Track the below URL for one-step submission https://juniperpublishers.com/online-submission.php 